\title{
Histological Observations of Annual Reproductive Cycle and Tidal Spawning Rhythm in the Female Porcupine Fish Diodon holocanthus
}

\author{
Toshiaki Fujita, ${ }^{* 1, \dagger}$ Wataru Hamaura, ${ }^{* 2}$ Akihiro Takemura, ${ }^{* 1}$ \\ and Kazunori Takano*1 \\ ${ }^{*}$ Sesoko Station, Tropical Biosphere Research Center, University of the Ryukyus, \\ Sesoko, Motobu, Okinawa 905-02, Japan \\ ${ }^{* 2}$ Kyokuyo Co., Ltd., Sonezaki, Kita-ku, Osaka 530, Japan
}

(Received January 13, 1997)

\begin{abstract}
Oocyte development was observed in the porcupine fish, Diodon holocanthus, to describe the annual reproductive cycle, and spawning with tidal rhythm, in Okinawa, southern Japan. On the basis of histological characteristics, the oocytes were divided into the following eight stages: the chromatinnucleolus, peri-nucleolus, yolk vesicle, primary yolk, secondary yolk, and tertiary yolk stages. Based on a monthly sampling the oocytes at the yolk vesicle stage first appeared in January. The oocytes laden with yolk were observed from April through June. After July, the ovaries were comprised of oocytes at the chromatin-nucleolus and peri-nucleolus stage. These results suggest that endogenous vitellogenesis in this species starts in January, and that exogenous vitellogenesis takes place from April through June. When the fish were collected according to the tidal phase (the spring and the neap tide) from May through August, the well-developed oocytes were observed with the spring tides from May through June. In contrast, the ovaries collected at the neap tide during the same period contained a small amount of the oocytes at the tertiary yolk stage and showed post-spawning features. Therefore, it is likely that $D$. holocanthus spawns between the spring and the neap tide.
\end{abstract}

Key words: ovary, reproductive cycle, tidal rhythm, porcupine fish, Diodon holocanthus

Oocyte formation in teleost fishes is a dynamic process that exhibits a diversity in oocyte development patterns among species. ") Many histological studies have been carried out to clarify the reproductive cycle of various fishes. ${ }^{(-8)}$ The process of oocyte formation has been generally categorized as synchronous, group-synchronous, and asynchronous. ${ }^{8,9)}$ Briefly, synchronous oocyte development is where all oocytes in an ovary develop synchronously, are ovulated all together, and no recruitment of the next oocyte group occurs. In group-synchronous oocyte development, two distinct oocyte groups of developing and immature stages are present in the ovary. Species belonging to this group have a relatively short spawning period, and spawn several times during their life. In asynchronous oocyte development, various stages of the developing oocytes exist in an ovary and the oocytes close to maturation are ovulated as a group. Generally, fishes of this group have a long spawning period.

Porcupine fishes live in the shallow waters of the temperate and tropical zones, and are characterized by many spines covering the whole body. Several ecological studies including spawning behavior in the aquarium have been performed in some species such as Diodon holocanthus, ${ }^{10)}$ Diodon histrix ${ }^{(1)}$ and Chiliomyctrus schoefi. ${ }^{12)}$ But, basic information on the physiology of these fishes is needed, since studies on the reproduction of porcupine fishes are limited.
Five porcupine fishes, $D$. holocanthus, $D$. liturosus, $D$. hystrix, D. eydouxii, and $C$. affinis, are known to inhabit the waters of Okinawa, southern Japan, where they are all commercially important. Among these species, $D$, holocanthus is the most common and easy to collect. In the present study, we observed the monthly change in the histology of ovarian features of this species in Okinawa to gain a better understanding of its annual reproductive cycle. Additionally, ovarian changes during the tidal phase were investigated, since puffer fishes Fugu niphobles and $F$. rubripes spawn around the new and the full moon period. ${ }^{13,14)}$

\section{Materials and Methods}

\section{Experimental Fish}

$D$. holocanthus were collected monthly along the coast of Sesoko Island, northern Okinawa, Japan, from April 1991 through June 1992, and weekly from May through August in 1994. They were kept in a 45 metric ton tank with running seawater in Sesoko Station, Tropical Biosphere Research Center, University of the Ryukyus. After anaesthetizing the fish in $0.01 \%$ ethyl $p$-amino benzoate solution, body weight (BW) and gonad weight (GW) were recorded. Gonad-somatic index (GSI: GW $\times 100$ / BW) were calculated.

\footnotetext{
${ }^{\dagger}$ Address for correspondence: Nanae Fish Culture Experimental Station, Faculty of Fisheries, Hokkaido University, Sakura 498, Nanae, Hokkaido 041-11, Japan.
} 


\section{Histological Procedures}

Pieces of the ovaries were fixed in Bouin's solution and then embedded in histoparaffin (m. p. $56-58^{\circ} \mathrm{C}$, Nakarai tesque, Japan). The embedded pieces were serially sectioned at $7 \mu \mathrm{m}$ and stained with Delafield's hematoxylin-eosin staining. Some sections were subjected to periodic acid shiff (PAS) reaction.

\section{Statistics}

Results were presented as means and their standard errors (SE). Significance between means was determined at the $p<0.05$ level by the student $t$-test.

\section{Results}

\section{Annual Change in GSI}

Figure 1 shows the annual GSI change of female $D$. holocanthus. GSIs from April through June are mean values of 1991 and 1992 since there were no significant differences $(p<0.05)$ between both years. GSI from January through March was less than 1.0. Afterward, this value reached $3.1 \pm 1.4$ in April and increased significantly to reach its peak $(8.6 \pm 1.4)$ in May. A rapid decrease in GSI was observed in June ( $3.61 \pm 1.1)$, and maintained values of less than 1.0 during the following months.

\section{Morphological Observation of Oocyte Development}

Following the oocyte stage in plaice, Liopsetta obscul $a^{4}{ }^{4}$ the development process in $D$. holocanthus was divided into the following eight stages:

Chromatin-nucleolus stage (Fig. 2a)

The oocytes in this stage, about $20 \mu \mathrm{m}$ in diameter, are observed just beneath the surface of ovigerous lamellae throughout the year. Ooplasm was thin compared with the whole oocyte, and a large nucleus occupied most of the oocyte. In the nucleus, chromatin-reticulum accompanying

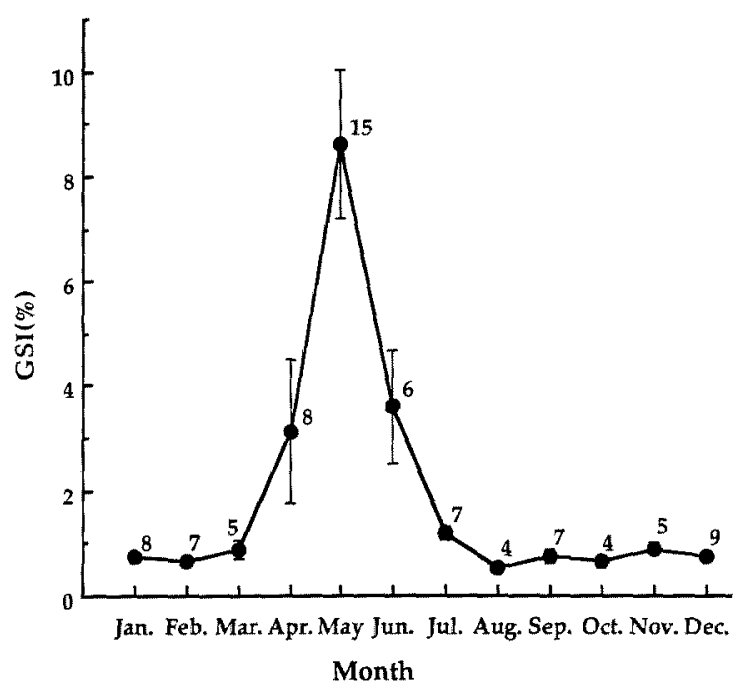

Fig. 1. Annual change in female GSI.

Closed circles show mean GSI of each month. Error bars indicate standard error. Numbers show fish collected in each month. chromatin-nucleolus were observed.

Peri-nucleolus stage (Fig. 2b \& c)

The oocytes in this stage were also observed throughout the year, ranging from 20 to $180 \mu \mathrm{m}$ in diameter. They were characterized by many nucleoli distributed along the periphery of the nuclear membrane. At the beginning of this stage, the ooplasm was deeply stained with hematoxyline. As the ooplasm increased in volume with oocyte growth, it decreased gradually in affinity with hematoxylin. A thin follicle layer was first observed around the oocyte.

Yolk vesicle stage (Fig. $2 \mathrm{~d} \&$ e)

When the diameter of the oocytes was over $180 \mu \mathrm{m}$, yolk vesicles a positive to PAS reaction began to appear in the ooplasm. As the oocyte grew, yolk vesicles increased in number and volume rapidly. The follicle layer could be detected clearly and the vitelline envelope was evident.

Primary yolk stage (Fig. 2f)

The oocyte at this stage ranged from 350 to $440 \mu \mathrm{m}$ in $\mathrm{di}$ ameter. A round nucleus, about $120 \mu \mathrm{m}$ in diameter, was located in the center of the oocyte. Yolk vesicles and oil droplets increased in number and volume, and spread throughout the ooplasm. Yolk globules, which were strongly dyed with eosin, began to appear as minute granules in the periphery. The follicle layer became thicker. The vitelline envelope, more than $6 \mu \mathrm{m}$ in thickness, was observed clearly as a membrane between the ooplasm and the follicle layer.

Secondary yolk stage (Fig. $2 \mathrm{~g}$ )

The diameter of the oocyte at this stage ranged from 430 to $580 \mu \mathrm{m}$. Yolk globules were further accumulated in the ooplasm. Yolk vesicles were arranged as several layers in the periphery of the ooplasm. Oil droplets formed a few rings in the ooplasm around the nucleus.

Tertiary yolk stage (Fig. $2 \mathrm{~h}$ )

The oocytes at this stage reached about $900 \mu \mathrm{m}$ in diameter. The oocyte was filled with many large yolk globules of about $35 \mu \mathrm{m}$ in diameter. The yolk vesicles formed one or two layers in the periphery of the ooplasm. A nucleus of about $135 \mu \mathrm{m}$ in diameter was still located in the center of the oocyte. Toward the end of this oocyte stage, the vitelline envelope became markedly thick and reached more than $50 \mu \mathrm{m}$ in the most advanced oocytes. Atretic oocyte (Fig. 2i)

The size of this oocyte was almost the same as that of the tertiary yolk stage. However, its features were different: degradation of the vitelline envelope and yolk globules, and no nucleus were observed.

Ovulatory follicle (Fig. 2j)

The Follicle layer shrank after ovulation. This empty follicle was about $250 \mu \mathrm{m}$ and $200 \mu \mathrm{m}$ in the long and short axis, respectively.

The maturational phase (migratory nucleus and maturation stage) oocytes were not observed in all fishes collected in this study.

\section{Annual Change in Oocyte Composition}

The oocytes in each stage were counted under the microscope, in order to determine their percentage of oocyte composition in the ovary. The oocytes at the chromatinnucleolus stage were excluded from counting, since they were too numerous to count. 


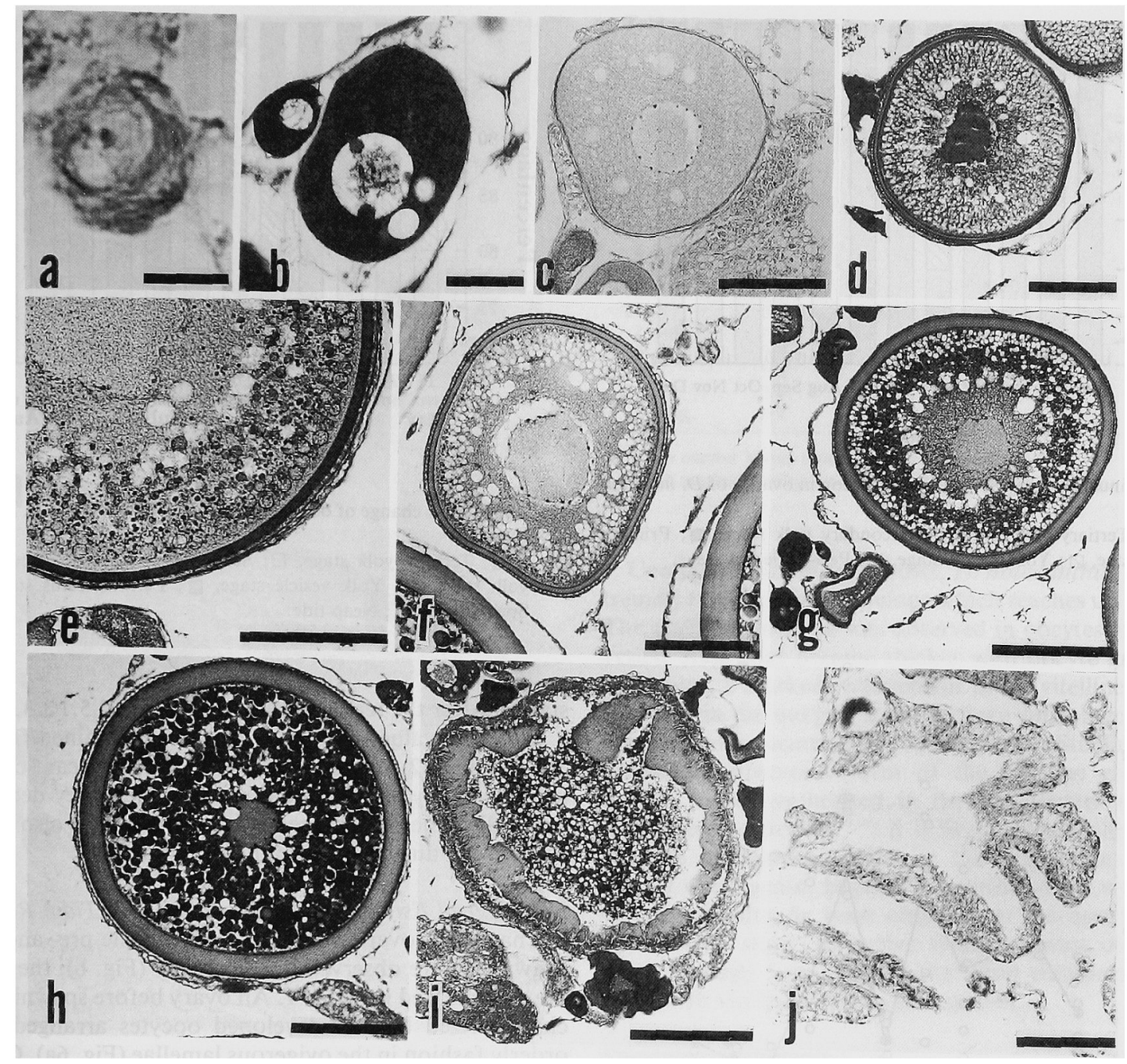

Fig. 2. Histological stage classification of developing oocytes.

a; chromatin-nucleolus stage ( $\mathrm{bar}=10 \mu \mathrm{m})$, b; early peri-nucleolus stage $(\mathrm{bar}=50 \mu \mathrm{m})$, c; late peri-nucleolus stage (bar $=100 \mu \mathrm{m})$, d; yolk vesicle stage $(\mathrm{bar}=150 \mu \mathrm{m})$, e; Yolk vesicle stage with PAS $(\mathrm{bar}=100 \mu \mathrm{m})$, f; primary yolk stage $(\mathrm{bar}=150 \mu \mathrm{m})$, g; secondary yolk stage $(\mathrm{bar}=200$ $\mu \mathrm{m}), \mathrm{h}$; tertiary yolk stage $(\mathrm{bar}=250 \mu \mathrm{m}), \mathrm{i}$; atretic oocyte $(\mathrm{bar}=250 \mu \mathrm{m}), \mathrm{j}$; ovulatory follicle $(\mathrm{bar}=100 \mu \mathrm{m})$.

Figure 3 shows the annual change of oocyte composition. The ovaries from January through March contained oocytes at the peri-nucleolus and yolk vesicle stages. The percentage of oocytes at the yolk vesicle stage increased gradually during these months. In April, oocytes laden with yolk were first observed, with mean values of $2.6,1.7$ and $4.4 \%$ in the primary, secondary and tertiary yolk stages, respectively. All the ovaries in May contained oocytes at the tertiary yolk stage. The percentage of this oocyte increased, showed $12.0 \pm 1.8 \%$ in this month. Six of eight fish collected in this month contained a number of oocytes at the tertiary yolk stage, but very few at the primary and secondary yolk stages, and oocyte composition in the ovaries could divided into two groups: the immature oocytes without true yolk and the developed ones at the tertiary yolk stage. In June, the mean value of the peri-nucleolus stage increased and that of the tertiary yolk stage decreased. Four fish in this month had no oocytes at the yolk stage. However, most of the others contained oocytes at the tertiary yolk stage and their oocyte composition could be divided into two groups, similar to the fish collected in May. In addition, most of them contained atretic oocytes coinciding with the yolk vesicle and yolk globule stages. Ovulatory follicles (Fig. 2J) were observed in the three ovaries. From July through December, all the oocytes in the ovaries were at the peri-nucleolus stage.

\section{Weekly Change in GSI}

To clarify the relationship between spawning and the tidal rhythm, fish were collected at the spring (ST) and the neap (NT) tides from 11 May through 2 August, 1994 (Fig. 4). The fish collected on 11 May (ST) had GSI from 1.4 to 9.0. GSI changed less than 10.0 from 19 May (NT) through 4 June (NT). Peaks were observed on 11 June (ST) and 24 June (ST) and each mean value was 14.0 and 15.0, respectively. Gonad-somatic index decreased to 3.5 on 18 June (NT) between STs. Afterward, GSI decreased gradually and was 6.9 on 2 July (NT) and 2.2 on 10 July 


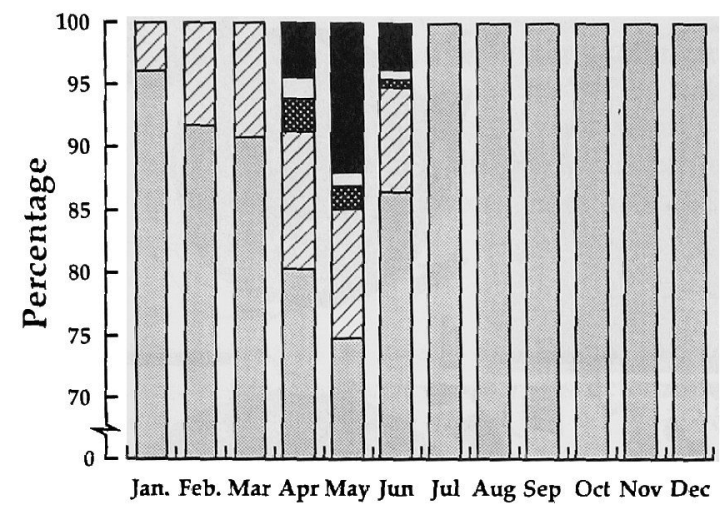

Month

Fig. 3. Annual change of oocyte composition in ovaries of $D$. holocanthus.

- Tertiary yolk stage, $\square$; Secondary yolk stage, ; Primary yolk stage, $\square$; Yolk vesicle stage, $\square$; Peri-nucleolus stage.

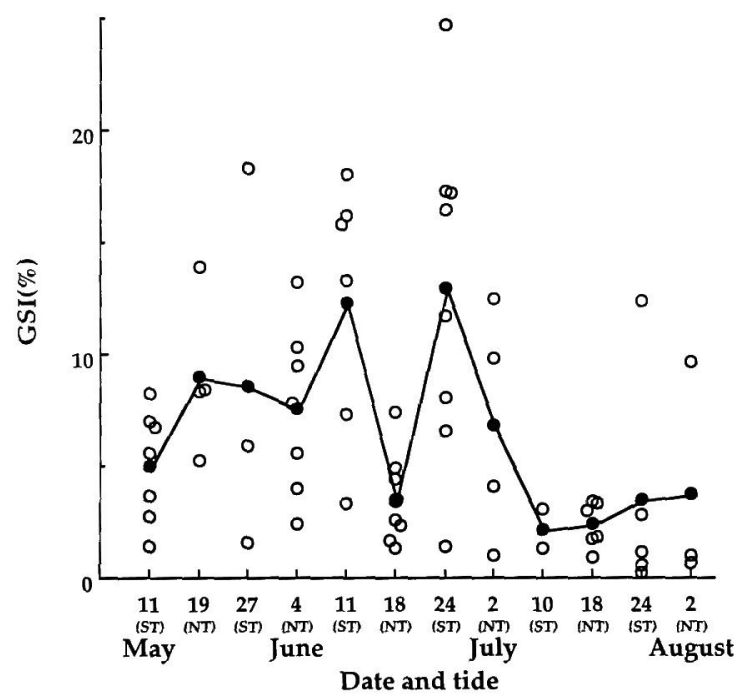

Fig. 4. Weekly change in female GSI from May through August in 1994.

Closed and open circles in the figure show mean and individual GSI in each sampling, respectively. ST; Spring tide, NT; Neap tide.

(ST). Subsequently GSI was less than 5.0. In addition, the ratio of male fish was approximately $20 \%$ (16 males out of 79 individuals) from 11 May through 2 August.

\section{Weekly Change in Oocyte Composition}

A weekly change in oocyte composition is shown in Fig. 5. During 11 May (ST) through 27 May (ST), the percentage of yolk stage oocytes increased gradually. On 4 June (NT), oocytes at the tertiary yolk stage decreased and ovulatory follicles were observed in one fish. After 11 June (ST) and 24 June (ST) the percentage of tertiary yolk stage oocytes increased to $10.3 \pm 1.7 \%$ and $12.1 \pm 3.2 \%$, respectively. The neap tide on 18 June between STs had a low percentage of the tertiary yolk stage. In addition, most of the fishes had no oocytes at the primary and secondary yolk

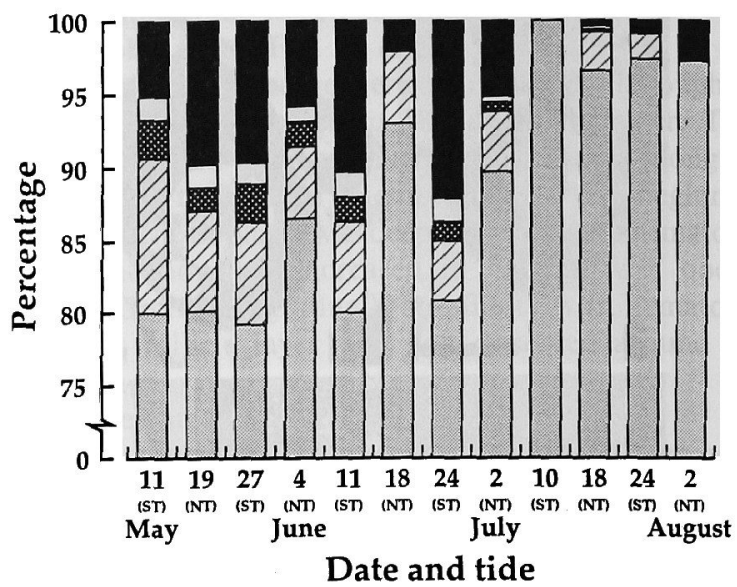

Fig. 5. Weekly change of oocyte composition in ovaries of $D$. holocanthus.

口; Tertiary yolk stage, $\square$; Secondary yolk stage, 용 ; Primary yolk stage, $\square$; Yolk vesicle stage, $\square$; Peri-nucleolus stage. ST; Spring tide, NT; Neap tide.

stages. After the tertiary yolk stage reached $5.1 \pm 3.4 \%$ on 2 July, low values in this stage were maintained from 10 July through 2 August. There were no significant changes in the primary and secondary yolk stages; they decreased gradually. The percentage of yolk vesicle stage also tended to decrease during the sampling period.

Histological Estimation of Spawning with Tidal Rhythm

Changes in ovarian features between the pre- and postspawning were observed histologically (Fig. 6); the results are summarized in Table 1. An ovary before spawning was characterized by well-developed oocytes arranged in an orderly fashion in the ovigerous lamellae (Fig. 6a). Ovaries showing pre-spawning features appeared on 11, 19, and 27 May. After spawning, residual eggs in the ovarian cavity and physical deformation of the ovigerous lamellae were observed (Fig. 6b). Those features of the post-spawning first appeared on 4 June (NT), and were observed frequently between NP and ST thereafter. Further, active vitellogenesis was not observed in all of the fishes having postspawning features.

\section{Discussion}

\section{Annual Reproductive Cycle}

From July through December, the ovaries of $D$. holocanthus were comprised of only the oocytes at the chromatinnucleolus and the peri-nucleolus stages, although the number of oocytes seemed to increase gradually. From January, oocytes at the yolk vesicle stage were observed among the immature oocytes in all the ovaries. These observations show that the endogenous vitellogenesis of $D$. holocanthus starts from January in Okinawa. Oocytes laden with yolk first appeared in April until June, suggesting that exogenous vitellogenesis was actively progressing. Vitellogenin, a yolk precursor, is synthesized in hepatocytes, released into the circulation, and incorporated into developing oocytes. ${ }^{8,9)}$ During those months, the oocytes 


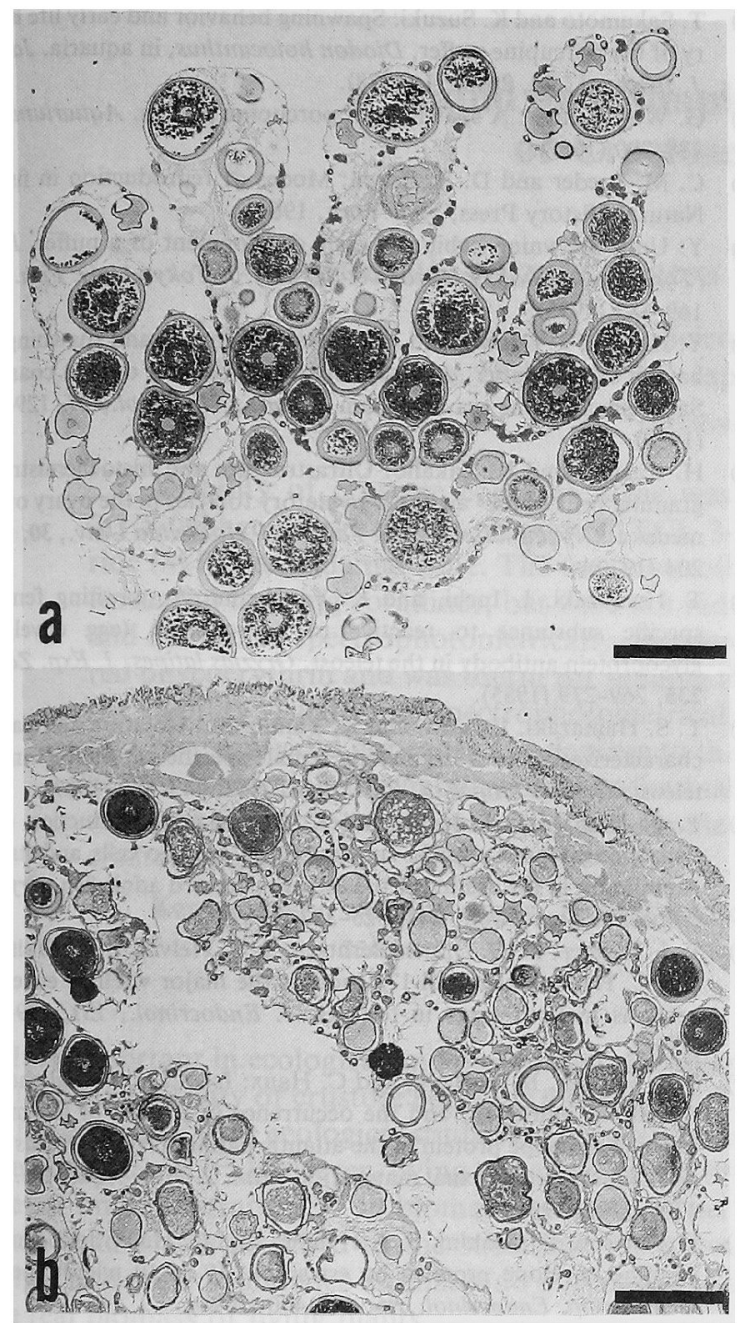

Fig. 6. Cross sections of ovaries of $D$. holocanthus. a; Ovary before spawning. Many vitellogenic oocytes are arranged in order in the ovigerous lamellae. b; Ovary after spawning. Ovigerous lamellae have lost their normal shape. Bars $=1 \mathrm{~mm}$.

were divided into two distinct groups, the oocytes at the tertiary yolk stage and immature yolk-less oocytes. This observation demonstrates that oocyte development in $D$. holocanthus is group synchronous; the fish spawns just once per year, since new recruitment from the immature oocyte crop seems not to occur. Some ovaries in June contained yolk-less oocytes and atretic oocytes but ovulatory follicles were also present in some ovaries. Kagawa and Takano ${ }^{15)}$ described characteristic features of the ovulated follicles in medaka, Oryzias latipes, histologically, histochemically, and cytologically, and proposed that the empty follicles existing in the ovaries after ovulation can be used as an indicator of spawning. Therefore, the ovulatory follicles appearing in the ovaries of $D$. holocanthus are also considered to be histological features of postspawning, and suggest that some fishes had spawned before that month. In June, the other fish still had well-developed oocytes. These differences in ovarian features among individuals in the same month suggest that several spawnings may have occurred between May and June.
Table 1. Histological feature of ovaries during spawning season in 1994

\begin{tabular}{|c|c|c|c|c|}
\hline \multirow[b]{2}{*}{ Date } & \multirow[b]{2}{*}{ Tide } & \multicolumn{3}{|c|}{ Number of fish } \\
\hline & & Total & $\begin{array}{c}\text { Residual } \\
\text { eggs }\end{array}$ & $\begin{array}{l}\text { Deformation }{ }^{* 2} \\
\text { of lamellae }\end{array}$ \\
\hline 11 May & ST & 7 & & \\
\hline 19 & NT & 4 & & \\
\hline 27 & ST & 3 & & \\
\hline 4 June. & NT & 7 & 3 & 3 \\
\hline 11 & ST & 6 & & \\
\hline 18 & NT & 8 & 3 & 4 \\
\hline 24 & ST & 8 & 1 & \\
\hline 2 Jul. & NT & 4 & 1 & 2 \\
\hline 10 & ST & 2 & & 1 \\
\hline 18 & NT & 6 & 3 & 6 \\
\hline 24 & ST & 5 & & 2 \\
\hline 2 Aug. & NT & 3 & & 2 \\
\hline
\end{tabular}

*1 Fish number having residual eggs in the ovarian cavity

*2 Fish number showing deformation of the ovigerous lamellae.

Compared with other teleosts, $D$. holocanthus has an extremely thick vitelline envelope which reaches up to $50 \mu \mathrm{m}$. The vitelline envelope was observed in oocytes at the yolk vesicle stage and became thicker with oocyte growth. In particular, a marked enlargement in the vitelline envelope occurred in the oocytes at the tertiary yolk stage, coinciding with yolk accumulation into oocytes. Similar to vitellogenin, a precursor form of the vitelline envelope is known to be synthesized in the hepatocytes under the influence of estrogen. ${ }^{16-25)}$ It is likely that synthesis of the vitelline envelope precursor in the hepatocytes precedes that of vitellogenin, because formation of the vitelline envelope had already been observed in the oocytes at the yolk vesicle stage. Its active synthesis must occur from April through June, because its rapid enlargement coincides with vitellogenesis in this species.

\section{Spawning Periodicity}

During the spawning season, $D$. holocanthus were collected every week according to the tidal phase. When the spawning of each fish was checked on the basis of changes in GSI and histological features of the ovaries, we noticed that the tidal periodicity is one of the important environmental factors that triggers the spawning of $D$. holocanthus. $D$. holocanthus collected at the spring tides from May through June had higher GSI reaching more than $15 \%$ and ovaries which contained oocytes at the tertiary yolk stage. In contrast, the fish collected at the neap tides during the same period showed relatively low GSI. Additionally, histological observations revealed that many ovaries had structural deformation of the ovigerous lamellae, and contained residual oocytes among immature oocytes. These are well known as typical features of the post-spawning ovary. The empty follicles, an indicator of ovulation, were also observed in the ovaries of $D$. holocanthus collected at the neap tide. Therefore, it is likely that this species spawns between the spring and the neap tide. Some fish, however, had high GSI and with many oocytes at the yolk stages, even at the neap tides. These fish may still have been accumulating yolk into the oocytes at that time and preparing for spawning at the following and appropriate tide. The two fish collected on 24 July and 2 August had many atretic oocytes at the yolk stage. These fish seemed 
to have missed the spawning of the year. It has been reported that the puffers $F$. niphobles and $F$. rubripes have a spawning bed, where the sex-ratio was considerably skewed toward males. ${ }^{13,14)}$ In case of $D$. holocanthus which was collected from 11 May through 2 August in 1994, there were only 16 males out of 79 . It is speculated that $D$. holocanthus has also specific spawning beds to which it migrates from regular habitats. This may be one reason why we could not collect females having ripe eggs.

In conclusion, $D$. holocanthus may develop oocytes toward the specific spring tide individually and spawn between the spring and the neap tide. If the spawning of this species is related to the tidal rhythm, it may be initiated from late May, and there are at least three peaks in the spawning as a population during the spawning season.

Acknowledgments The authors would like to thank the technical staff of Sesoko Station, Tropical Biosphere Research Center, University of Ryukyus, for maintaining the experimental fish. Thanks are due to emeritus professor K. Yamazato, Department of Science, University of the Ryukyus and to professor A. Hara, Nanae Fish Culture Experimental Station, Hokkaido University, for their useful discussion and encouragement. We are indebted to professor G. K. Iwama, Department of Animal Science, the University of British Columbia, for critical reading of this manuscript. This study is a contribution of Sesoko Station, Tropical Biosphere Research Center, University of the Ryukyus.

\section{References}

1) K. Selman and R. A. Wallace: Cellular aspects of oocytes growth in teleosts. Zool. Sci., 6, 211-231 (1989).

2) Y. Koya, S. Ohara, T. Ikeuch, S. Adachi, T. Matubara, and K. Yamauchi: The reproductive cycle of female Zoarces elongatus, a viviparous teleost. Bull. Hokkaido Nat. Fish. Res. Ins., 57, 9-20 (1993).

3) A. Takemura, K. Takano, and H. Takahashi: Reproductive cycle of a viviparous fish, the white edged rockfish, Sebastes taczanowskii. Bull. Fac. Fish. Hokkaido Univ., 38, 111-125 (1987).

4) K. Yamamoto: Studies on the formation of fish eggs I. Annual cycle in the development of ovarian eggs in the flounder, Liopsetta obscura. J. Fac. Sci. Hokkaido Univ., 12, 362-373 (1956).

5) K. Yamamoto: Studies on the formation of fish eggs II. Changes in the nucleus of the oocyte of Liopsetta obscura, with special reference to the activity of the nucleolus. J. Fac. Sci. Hokkaido Univ., 12, 375-390 (1956).

6) K. Yamamoto and F. Yamazaki: Rhythm of development in the oocyte of the goldfish, Carassius auratus. Bull. Fac. Fish. Hokkaido Univ., 12, 93-110 (1961).

7) K. Yamamoto, M. Omori, and K. Yamauchi: Oogenesis of the Japanese eel. Nippon Suisan Gakkaishi, 40, 9-15 (1974).

8) R. A. Wallace and K. Selman: Cellular and dynamic aspects of oocyte growth in teleosts. Amer. Zool., 21, 325-343 (1981).

9) V. deVlaming: Oocyte development patterns and hormonal involvement among teleosts, in "Control Processes in Fish Physiology" (ed. by J. C. Rankin, T. J. Pitcher and R. Duggan), Croom Helm, London, 1983, pp. 176-199.
10) T. Sakamoto and K. Suzuki: Spawning behavior and early life history of the porcupine puffer, Diodon holocanthus, in aquaria. Japan. J. Ichthyol., 24, 261-271 (1978).

11) G. Wolfsheimer: A spawning of porcupine puffers. Aquarium, 26, 288-290 (1957).

12) C. M. Breder and D. E. Rosen: Modes of reproduction in fishes, Natural History Press, New York, 1966.

13) Y. Uno: Spawning habit and early development of a puffer, Fugu (Torafugu) niphobles (Jordan et Snyder). J. Tokyo Univ. Fish., 41, 169-183 (1955).

14) Y. Honma, T. Ozawa, and A. Chiba: Maturation and spawning behavior of the puffer, Fugu niphobles, occurring on the coast of Sado island in the sea of Japan. Japan. J. Ichthyol., 27, 129-138 (1980).

15) H. Kagawa and K. Takano: Ultrastructure and histochemistry of granular cells of pre- and post-ovulatory follicles in the ovary of the medaka, Oryzias latipes. Bull. Fac. Fish. Hokkaido Univ., 30, 191204 (1979).

16) T. Hamazaki, I. Iuchi, and K. Yamagami: A spawning femalespecific substance to reactive to anti-chorion (egg envelope) glycoprotein antibody in the teleost, Oryzias latipes. J. Exp. Zool., 235, 269-279 (1985).

17) T. S. Hamazaki, I. Iuchi, and K. Yamagami: Isolation and partial characterization of a "spawning female-specific substance" in the teleost, Oryzias latipes. J. Exp. Zool., 242, 343-349 (1987).

18) T. S. Hamazaki, I. Iuchi, and K. Yamagami: Production of a "spawning female-specific substance" in hepatic cells and its accumulation in the ascites of the estrogen-treated adult fish, Oryzias latipes. J. Exp. Zool., 242, 325-332 (1987).

19) S. J. Hyllner, D. O. Oppen-Berntsen, J. V. Helvik, B. T. Walther, and $C$. Haux: Oestradiol-17 $\beta$ induces the major vitelline envelope proteins in both sexes in teleosts. J. Endocrinol., 131, 229-236 (1991).

20) S. J. Hyllner, B. Norberg, and C. Haux: Isolation, partial characterization, induction, and the occurrence in plasma of the major vitelline envelope protein in the atlantic halibut (Hippoglossus hippoglossus) during sexual maturation. Can. J. Fish. Aqua. Sci, 51, 1700-1707 (1994)

21) D. Larsson, G. Joakim, S. J, Hyllner, and C. Haux: Induction of vitelline envelope proteins by estradiol $17 \beta$ in 10 teleost species. Gen. Comp. Endocrinol., 96, 445-450 (1994).

22) K. Murata, I. Iuchi, and K. Yamagami: Synchronous production of the low-and high-molecular-weight precursors of the egg envelope subunits, in response to estrogen administration in the teleost fish Oryzias latipes. Gen. Comp. Endocrinol., 95, 232-239 (1994).

23) D. O. Oppen-Berntsen, E. Gram-Jensen, and B. T. Walther: Zona radiata proteins are synthesized by rainbow trout (Oncorhynchus mykiss) hepatocytes in response to oestradiol-17ß. J. Endocrinol., 135, 293-302 (1992).

24) D. O. Oppen-Berntsen, S. J. Hyllner, C. Haux, J. V. Helvik, and B. T. Walther: Eggshell zona radiata-proteins from cod (Gadus morhua): extra-ovarian origin and induction by estradiol-17 $\beta$. Int. J. Dev. Biol., 36, 247-254 (1992).

25) D. O. Oppen-Berntsen, S. O. Olsen, C. J. Rong, G. L. Taranger, P. Swanson, and B. T. Walther: Plasma levels of eggshell zr-proteins, estradiol-17 $\beta$, and gonadtropins during an annual reproductive cycle of atlantic salmon (Saimo salar). J. Exp. Zool., 268, 59-70 (1994). 